\title{
Look Before You Leap: Economics of Being an Omnichannel Retailer
}

\author{
Kushal Saha \\ Indian Institute of Management Calcutta, \\ Diamond Harbor Road, Kolkata 700104, India \\ E-mail: kushals13@email.iimcal.ac.in (Corresponding Author) \\ Subir Bhattacharya \\ Indian Institute of Management Calcutta, \\ Diamond Harbor Road, Kolkata 700104, India \\ E-mail: subir@iimcal.ac.in
}

\begin{abstract}
This paper investigates how the market gets segmented when an omnichannel retailer enters a market hitherto served by non-omnichannel retailers. The added value derived from the omnichannel flexibility is expected to draw more customers to an omnichannel retailer, luring them away from the incumbent non-omnichannel peers. However, the customers are expected to be heterogeneous in their valuation of the omnichannel flexibilities offered. Also, since acquiring omnichannel flexibility entails additional costs for service integration, the omnichannel aspirant is expected to charge a higher price from the customers than its non-omnichannel competitors. Our model considers both these factors, and derives analytical expression for the expected market share of the omnichannel retailer as a function of the price charged by the non-omnichannel peers, the extent of flexibility provided, and the cost of providing the same. Also, given the cost of service integration, we estimate the level of flexibility that an omnichannel retailer must offer if it wants to acquire a specific market share. The findings indicate that the associated integration cost imposes a restriction on the maximum market share an omnichannel entrant can aspire to capture.
\end{abstract}

Keywords: omnichannel, retail competition, retail performance, channel design, retail strategy

'Success in today's retail world is an increasingly multifaceted proposition. It's not enough to have a great online shopping experience or a brick-and-mortar store that keeps customers coming back. Rather, each retail channel needs to work in tandem, creating a shopping experience that's totally seamless'. - The Wall Street Journal (20 ${ }^{\text {th }}$ April, 2017)

\section{INTRODUCTION}

Over the last few years, 'Omnichannel' has become a buzzword in the retailing world. Omnichannel promises to offer an integrated view of the services offered by online and offline channels so that a customer can interchangeably, and seamlessly use services of both the channels to enhance her shopping experience during various stages of a purchase process - research, purchase, delivery, and post-purchase services (Abdulkader et al., 2018; Rey-garcía et al., 2018; Williams et al., 2014). The value proposition is expected to increase the propensity among the customers to buy from an omnichannel retailer. Extant channel literature predicts the omnichannel retailers to outperform their non-omnichannel competitors by offering "the right combination of experiences" as demanded by the customers (Bell et al., 2014; Brynjolfsson et al., 2013; Rigby, 2011).

The attractiveness of the enhanced shopping experience offered by an omnichannel retailer would depend on customer's perceived inconvenience when constrained to use a single channel during the entire shopping process. Customers are reported to be heterogeneous in this regard (Cattani et al., 2006). In addition, customers are also heterogeneous in terms of the values they ascribe to a particular omnichannel service. Introduction of 'try at home' service may make the purchase process convenient for customers living far from a physical store but may not excite others. These heterogeneities would not have any impact had the omnichannel retailer been able to offer the product at the same price as its non-omnichannel peers, as availability of additional flexibility at no additional cost would have pushed all the customers to the omnichannel retailer. However, becoming omnichannel entails additional cost to be incurred - on top of the cost of operating individual channels in isolation - to bring the two sets of services into a bouquet of integrated services (Larke et al., 2018; Hossain et al., 2017). The retailer needs to enhance its supply chain capabilities, augment logistics competence, improve operational efficiency, increase visibility across channels, and ensure perfect integration between channels (Hansen \& Sia, 2015; Simone \& Sabbadin, 2017). Thus, efforts to create harmonious shopping experience across channels can become expensive. Additionally, eroding margins due to "aggressive (some would say irrational, uneconomic or even predatory) product and delivery pricing on the part of [retailers] that value hyper-growth over profits" often pushes the retailers further into the vicious cycle of worsening financial performance (Dennis, 2018). Unless an omnichannel retailer follows a predatory pricing policy, it would need to charge the customers a higher price to recover this additional cost of providing 'omnichannel' flexibility (Zacks Equity Research, 2017). XXL, one of the largest sports retailer in the Nordic region, "is very skeptical in doing this for free" (Gunnilstam, 2016). UK-based retailer John Lewis charges additional $£ 2$ for orders of less than $£ 30$ placed through their "click and collect, ordering online and picking up in store" facility ("Click \& Collect from Our 
Shop," n.d.; Ruddick, 2015). A higher retail price, in turn, would reduce a customer's incentive to buy from the omnichannel player. Thus, competitiveness of an omnichannel retailer would depend on the cost vs. (service) benefits trade-off (Piotrowicz \& Cuthbertson, 2014), i.e., the balance between the additional price it charges vis-à-vis the enhanced convenience it offers.

As provisioning of additional convenience comes at a cost, "designing [omnichannel model] to achieve optimal value requires improvements in service to the level at which the customer is willing to pay for the additional cost of that service" (Larke et al., 2018). Thus, an omnichannel retailer faces the issue of deciding how much flexibility should be provided at what cost so as to attract a sufficient number of customers at the increased price. This paper is an attempt to investigate the trade-off between omnichannel services provided and the enhanced price to be charged for arranging the same, and its consequent impact on the performance of an omnichannel retailer in a competitive environment. We observe that, given the cost of service integration (a highly efficient retailer would have lower cost of service integration and vice versa), an omnichannel retailer can expect to achieve only a certain share of the target market. Thus, rather than capturing the entire market by driving out the competition, omnichannel retailers are more likely to coexist with their non-omnichannel counterparts.

\section{LITERATURE REVIEW}

Successful implementation of omnichannel strategy is a complex task given the strategic and operational challenges it entails. Provisioning of a multitude of touchpoints, situated across a variety of channel formats, introduces additional challenges (Ilk et al., 2018) leading to increased complexity in managing such a business model (Ailawadi \& Farris, 2017; von Briel, 2018). Consistent management of retailing mix across synchronized touchpoints is considered essential in enabling omnichannel journeys (Huré et al., 2017). To ensure superior brand experience, omnichannel aspirants must discard the siloed nature of channel management (Picot-Coupey et al., 2016) and seamlessly integrate different channels. This cannot be achieved unless the concerned player is able to ensure alignment of channel objectives using appropriate financial and operational metrics, availability of a unified view of customers across channels, and resolution of issues related to organizationwide inventory visibility (Ailawadi \& Farris, 2017; Piotrowicz \& Cuthbertson, 2014). In an attempt to redesign customer shopping experience, the concerned retailer needs to successfully integrate necessary digital innovation especially in the areas of information provisioning and product fulfillment - to its core business and still ensure close collaboration between different channels (Bell et al., 2014).

Quite a few researches have looked into various operational challenges of becoming omnichannel. Ishfaq et al. (2016) discuss how the physical distribution processes of an offline retailer can be realigned to integrate online channel into its business model in achieving omnichannel objectives. Picot-Coupey et al. (2016) attempt to address similar concerns for online retailers. A similar exercise involving multichannel retailers is taken up by Hübner et al. (2016) where they offer a set of guidelines to effectively manage a multichannel retailer's transition towards developing omnichannel fulfillment capabilities. Some other operational aspects from an omnichannel context - e.g., effective online and offline information delivery (Gao \& Su, 2017b), configuring omnichannel fulfilment process (Wollenburg et al., 2018), self-order technology (Gao \& Su, 2018), buyonline-and-pick-up-in-store (Gao \& Su, 2017a), crosschannel integration (Y. Li et al., 2018; Shen et al., 2018), sources of online-offline synergies and tensions (Wiener et al., 2018), dynamic pricing of inventories (Harsha et al., 2019), and product placement strategy (Gu \& Tayi, 2017) have also been studied in detail in the existing literature.

Overcoming the operational challenges would need investments in acquiring necessary functional and technological capabilities. Investments in enhancing supply chain capabilities are considered to be crucial to ensure perfect integration of physical and information flow in resolving issues related to "product availability, returns, delivery options, reverse flows, and inventory management across channels" (Piotrowicz \& Cuthbertson, 2014). Additionally, "new processes, networks and infrastructure, information systems and [organizational] structures" are to be developed to create a system highly responsive to customer needs (Saghiri et al., 2018). Procurement of new technological infrastructures and related software, in-store technologies would also require significant investments (Piotrowicz \& Cuthbertson, 2014; Rigby, 2011). Moreover, synchronization efforts expended by retailers in ensuring consistent management of retailing mix across channels impact the value delivered to the customers (Huré et al., 2017). Customer patronage intentions have been found to be positively correlated with the perceived level of channel integration (Zhang et al., 2018). Higher level of synchronizing/ integrating efforts would create higher values for both customers and retailers but would come at an increased cost.

Clearly, becoming an omnichannel retailer - and staying there - has cost implications. Managing an omnichannel model "can cost a lot more than simply running stores" (Petersen, 2017). The cost would depend, on one hand, on the number and complexities of the services being integrated, and on the other hand, on the inherent efficiency of the retailer to integrate services. The retailer has to recover the cost of omnichannel operation by charging a higher price from the customer. Since different customers value omnichannel services differently, charging a higher retailer price would dissuade a fraction of the customers from purchasing from an omnichannel retailer. Sustainability of an omnichannel business model would depend on its ability to attract enough number of customers in the face of competition posed by its non-omnichannel rivals and still operate profitably (Zacks Equity Research, 2017).

While the extant literature is quite rich in (a) establishing the need for retailers to become omnichannel and (b) identifying the operational challenges to be encountered in the process, the implication of the cost of becoming omnichannel has only been passingly referred to. This paper attempts to address this research gap. More specifically, this paper dwells on the following set of questions. How does the market get segmented when an omnichannel retailer enters a market currently served by non-omnichannel retailers? How does the extent of flexibility offered impact an omnichannel retailer's market share? Also, given the inherent efficiency of integration of 
an omnichannel retailer, and cost functions for integration, what amount of integration the retailer must ensure to target a specific market share?

\section{THE MODEL}

We consider a market currently being served by a set of offline and online retailers. To facilitate the purchase process, these retailers offer a set of offline or online services, respectively, to the customers. All the retailers are assumed to be offering the same product and, hence, it is fair to assume that none can afford a price premium on a sustained basis. In other words, all the existing retailers are being assumed to be offering an identical product at an identical price. We represent the incumbent nonomnichannel retailers by a representative retailer $R_{1}$ offering the product at a retail price $p_{1}$.

A customer's decision - whether to purchase the product or not - depends on the value she expects from the product and the total cost she has to incur in purchasing it. A purchase process would involve both financial and nonfinancial costs. The financial aspect of it is represented by the retail price the customer has to pay for the product. The non-financial component refers to the effort a customer has to make in completing the purchase process. We hereafter refer to this non-financial component as the 'effort cost' of purchase. The 'effort-cost' is customer-specific as different customers would perceive different levels of effort to complete a purchase process.

Table 1 Notations used

\begin{tabular}{|c|c|}
\hline Notation & Description \\
\hline$R R_{1}$ & Existing/incumbent retailer serving the market \\
\hline$R_{2}$ & The retailer introducing omnichannel services \\
\hline$U_{1}$ & Net utility derived by a customer from $R_{1}$ \\
\hline$U_{2}$ & Net utility derived by a customer from $R_{2}$ \\
\hline$R$ & $\begin{array}{l}\text { Reservation price of the product across the target } \\
\text { customers }\end{array}$ \\
\hline$p_{1}$ & Retail price at which $R_{1}$ offers the product \\
\hline$p_{2}$ & Retail price at which $R_{2}$ offers the product \\
\hline$h_{1}$ & $\begin{array}{l}\text { Random variable denoting effort cost required to } \\
\text { purchase the product from } R_{1} ; \text { Uniformly } \\
\text { distributed over the interval }[0, H], H>0\end{array}$ \\
\hline$h_{2}$ & $\begin{array}{l}\text { Random variable denoting effort cost required to } \\
\text { purchase the product from } R_{2}\end{array}$ \\
\hline$\beta$ & Effort reduction factor, i.e., $h_{2}=\beta \times h_{1}$ \\
\hline$b$ & $\begin{array}{l}\text { The lower support of } \beta \text { 's distribution, i.e., } \beta \sim \\
\text { Unif }[b, 1] \text { where } 0 \leq b \leq 1\end{array}$ \\
\hline$c_{1}$ & $R_{1}$ 's cost of serving a customer \\
\hline$\eta$ & $\begin{array}{l}\text { The efficiency coefficient of omnichannel } \\
\text { integration for } R_{2}\end{array}$ \\
\hline
\end{tabular}

We use a linear utility function similar to the one used in Cattani et al. (2006) where the utility a customer derives decreases with the effort cost to be incurred during the purchase process and the retail price of the product. A customer derives net utility

$$
U_{1}=R-h_{1}-p_{1}
$$

while purchasing the product from retailer $R_{1}$ at a price $p_{1} . R$ is the reservation price for the product and, consistent with relevant literature (Cattani et al., 2006; Vandenbosch \& Weinberg, 1995), the target customers are assumed to be homogenous with respect to their reservations price of the concerned product. $R$ is assumed to be greater than $p_{1}$ to avoid the trivial situation where no customer is able to derive positive utility from retailer $R_{1} . h_{1}$ represents the effort cost that needs to be incurred while purchasing from $R_{1}$ and is customer specific. To capture the customer heterogeneity in terms of the 'effort cost', we assume $h_{1}$ to follow a continuous uniform distribution over the interval $[0, H](H>0)$. Thus, a customer with her effort cost higher than $\left(R-p_{1}\right)$ would not be able to derive positive utility from retailer $R_{1}$ and vice versa. We further assume $0<R-$ $p_{1}<H$ implying that a share of the target market - not the whole of it - would derive positive utility from retailer $R_{1}$. The market share that retailer $R_{1}$ manages to capture is given by the probability that a randomly selected customer is able to derive positive utility from retailer $R_{1}$, and hence buy the product from it. Given that retailer $R_{1}$ faces a downward sloping demand curve, this probability is given by:

$$
\begin{gathered}
\operatorname{Pr}\left\{U_{1}>0\right\}=\operatorname{Pr}\left\{R-h_{1}-p_{1}>0\right\} \\
=\operatorname{Pr}\left\{h_{1}<R-p_{1}\right\} \\
=\frac{\left(R-p_{1}\right)}{H} .
\end{gathered}
$$

Let us now consider the entry of an omnichannel retailer $R_{2}$ into the market. Instead of being constrained to use either offline or online services, the customers can now pick and choose from a bouquet of offline and online services while buying from $R_{2}$. It is expected that this newfound flexibility would make the purchase process more convenient by reducing their 'effort cost' of purchase. Let $h_{2}$ be a customer's 'effort cost' while purchasing from retailer $R_{2}$. Clearly, for any customer, $h_{2} \leq h_{1}$. Had retailer $R_{2}$ been able to bring down the effort cost and still be charging the same price $p_{1}$ as charged by $R_{1}$, all the customers would have preferred $R_{2}$ because of higher utility. However, the omnichannel retailer needs to have necessary infrastructures and mechanisms in place for integrating services across channels in order to reduce the effort cost. Thus, provisioning of 'omnichannel' flexibility entails an additional cost which the retailer $R_{2}$ is expected to recover by setting the omnichannel retail price $p_{2}$ higher than $p_{1}$ (i.e., $\left.p_{2}>p_{1}\right)$. It is assumed that the price differential $\left(p_{2}-p_{1}\right)$ per unit of product sold serves only to recover the cost of providing omnichannel services. In other words, $R_{1}$ and $R_{2}$ are assumed to enjoy same profit margin per unit of product.

Let $\beta\left(=\frac{h_{2}}{h_{1}} \leq 1\right)$ be the effort reduction factor by which the effort cost of a customer would decrease due to the availability of omnichannel services. Thus the effort cost a customer would have to incur to purchase from retailer $R_{2}$ is $h_{2}=\beta h_{1}$. The utility a customer expects to derive from retailer $R_{2}$ is given by:

$U_{2}=R-\beta h_{1}-p_{2}$ 
Introduction of omnichannel flexibility would affect different customers differently. While the offered flexibility could make the purchase process extremely smooth and effortless for some customers, at the other extreme, the added flexibility may not make much of a difference for some others. Thus the customers can be assumed to be heterogeneous in terms of how the introduction of omnichannel services impacts their effort costs. We capture this customer heterogeneity by assuming $\beta$ to follow a continuous uniform distribution over the interval $[b, 1](0 \leq$ $b \leq 1) . b$ is 0 where the omnichannel retailer arranges full integration of all the online and offline services and offers it as a common bouquet of services to the customer to facilitate seamless movement between the channels during the shopping process. This is the full flexibility and, thus, the ideal omnichannel scenario. However, in reality, most of the omnichannel retailers offer partial flexibility by integrating only some of the services (for example, buy-online-pick-upat-store, try at home, etc.). In these situations the flexibility $b$ offered will be $0<b<1$.

Given the extent of flexibility $b$ offered by the retailer $R_{2}$, a randomly selected customer will experience an effort reduction factor $\beta$ within $[b, 1](0 \leq b \leq 1)$ with equal probability. The lower support of $\beta$ 's distribution is taken to be $b$ as there will be some customers who would exploit the flexibility offered to its fullest. A $\beta$ value of 1 would imply that the omnichannel services have not make any impact on the concerned customer's purchase experience. It may be noted that $h_{1}$ and $\beta$ are independent of each other. Two customers incurring same effort cost while purchasing from $R_{1}$ might value omnichannel services differently and, as a result, might experience different effort reduction while purchasing from $R_{2}$.
Each customer is assumed to have ex-ante knowledge about the effort cost she would incur while purchasing the product from retailers $R_{1}$ or $R_{2}$ and would, accordingly, engage in strategic retailer selection. A customer would purchase the product from the retailer who provides her with higher positive utility. The probability that a randomly selected customer derives positive utility from retailer $R_{2}$ is given by:

$$
\operatorname{Pr}\left\{U_{2}>0\right\}=\operatorname{Pr}\left\{\beta h_{1}<R-p_{2}\right\} .
$$

The corresponding probability $\operatorname{Pr}\left\{U_{1}>0\right\}$ for retailer $R_{1}$ was mentioned to be $\operatorname{Pr}\left\{h_{1}<R-p_{1}\right\}$ in Equation (2).

As $h_{1}$ and $\beta$ are independent of each other, the target customers can be assumed to be uniformly distributed across the rectangle represented by $\left\{\left(h_{1}, \beta\right) \mid h_{1} \in[0, H], \beta \in[0,1]\right\}$. There will be three lines of indifference. Customers located to the left of the straight line $U_{1}=0$ or $h_{1}=R-p_{1}$ derive positive utility from retailer $R_{1}$ and those on the right of it fail to do so. The line of indifference denoted by $U_{2}=0$ or $\beta=\frac{\left(R-p_{2}\right)}{h_{1}}$ is a rectangular hyperbola with customers located below it deriving positive utility from retailer $R_{2}$. The third line of indifference is given by the $U_{1}=U_{2}$ or $=1-\frac{\left(p_{2}-p_{1}\right)}{h_{1}}$. Customers located above this line would derive higher utility from retailer $R_{1}$ than retailer $R_{2}$ and vice versa. These three lines of indifference intersect at the point $\left(R-p_{1}, \frac{R-p_{2}}{R-p_{1}}\right)$. We consider all the three lines of indifference together in Figure $\mathbf{1}$ to see how the market gets split when both the retailers vie for their respective market shares.

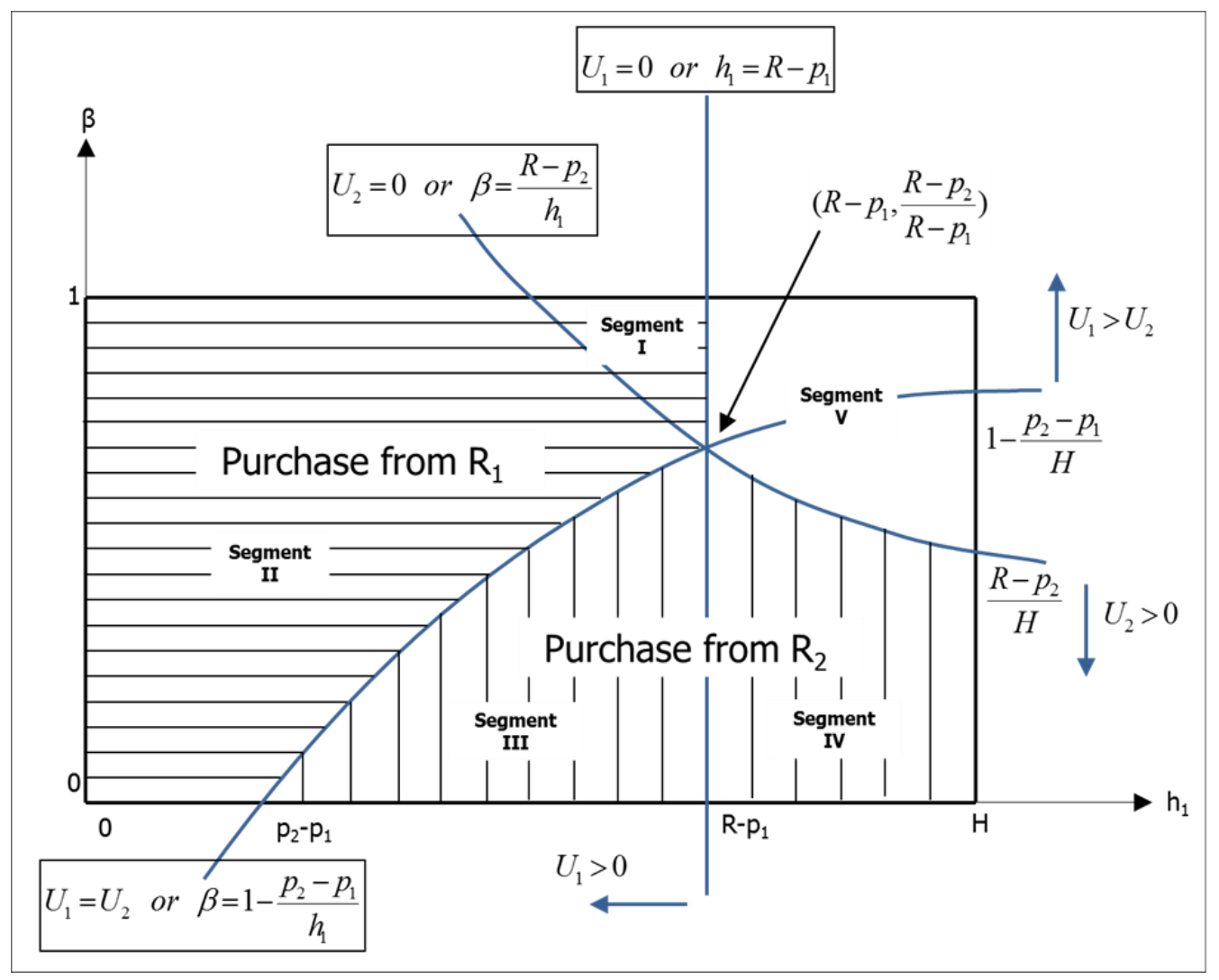

Figure 1 Market segmentation with incumbent $\mathrm{R}_{1}$ and omnichannel $\mathrm{R}_{2}$ serving the market 
Introduction of omnichannel services into a market currently being served by non-omnichannel retailers spilts the market into five segments:

i. Segment I: Customers who derive positive utility from retailer $R_{1}$, but not from retailer $R_{2}$

ii. Segment II: Customers who derive positive utility from both retailers $R_{1}$ and $R_{2}$, but higher utility from retailer $R_{1}$

iii. Segment III: Customers who derive positive utility from both retailers $R_{1}$ and $R_{2}$, but higher utility from retailer $R_{2}$

iv. Segment IV: Customers who derive positive utility from retailer $R_{2}$, but not from retailer $R_{1}$

v. Segment V: Customers who fail to derive positive utility from either of the retailers

Thus, customers belonging to segments I and II will continue to purchase from the incumbent retailer $R_{1}$ even after the introduction of omnichannel services. Customers belonging to segment $\mathrm{V}$ will stay away from the market. Omnichannel retailer $R_{2}$ 's market share will come from segments III and IV. Segment III represents the customers retailer $R_{2}$ manages to lure away from the incumbent retailer $R_{1}$. Segment IV represents the customers who were not purchasing from retailer $R_{1}$ but would now purchase from retailer $R_{2}$. Thus segment IV represents the increase in the product's market penetration due to introduction of omnichannel services.

\section{MODEL ANALYSIS}

\subsection{Full Omnichannel Flexibility $(b=0)$ at Price $p_{2}$}

Assume that the retailer $R_{2}$ targets full flexibility ( $b=$ 0 ) and sets the price $p_{2}$ accordingly to salvage the cost. We would like to see how the market shares of $R_{1}$ and $R_{2}$ get affected as $p_{2}$ goes up in comparison to $p_{1}$. To determine the market shares captured by the retailers $R_{1}$ and $R_{2}$, charging prices $p_{1}$ and $p_{2}$ respectively, we need to consider the contributions made by the segments identified above. All proofs have been provided in the appendix.

Proposition 1: When both $R_{1}$ and $R_{2}$ operate in the market at retail prices $p_{1}$ and $p_{2}$, respectively, (a) the market share of $R_{1}$ is given by $\frac{1}{H}\left(p_{2}-p_{1}\right)\left\{1+\ln \left(\frac{R-p_{1}}{p_{2}-p_{1}}\right)\right\}$, and (b) the market share of $R_{2}$ is given by $\frac{1}{H}\left[\left(R-p_{2}\right)\{1+\right.$ $\left.\left.\ln \left(\frac{H}{R-p_{1}}\right)\right\}-\left(p_{2}-p_{1}\right) \ln \left(\frac{R-p_{1}}{p_{2}-p_{1}}\right)\right]$.

By proposition 1, the market share of $R_{2}$ falls sharply as $p_{2}$ drifts away from $p_{1}$. Let us consider a numerical example with $R=10$ and $H=8$. Let the incumbent retail price $p_{1}$ be set at 6.5. Figure 2 shows the market shares of $R_{1}$ and $R_{2}$ as $p_{2}$ changes. $R_{1}$ and $R_{2}$ enjoy markets shares of $18.41 \%$ and $56.34 \%$, respectively, when $p_{2}=7$. However, when $p_{2}=7.5$, the corresponding market shares become $28.16 \%$ and $41.42 \%$, respectively.

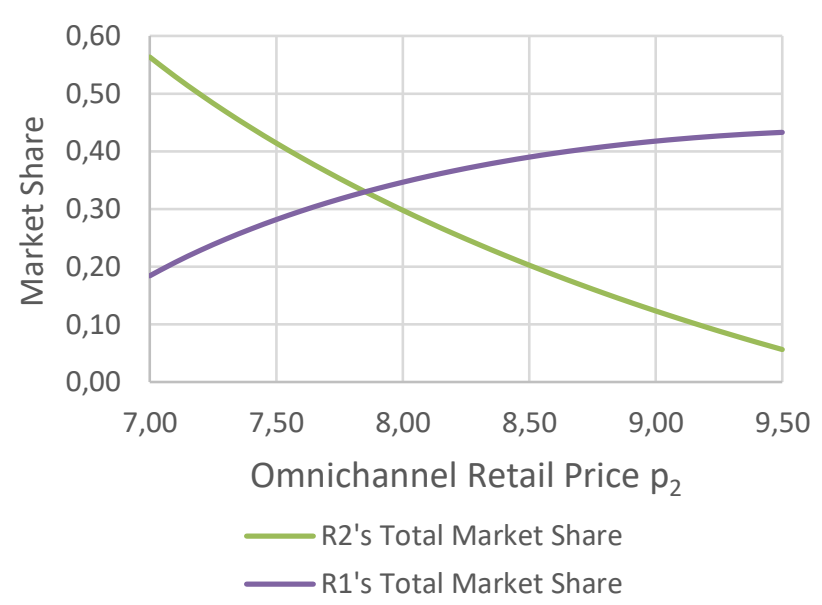

Figure $2 \mathrm{R}_{1}$ 's and $\mathrm{R}_{2}$ 's market shares when $\mathrm{R}=10, \mathrm{H}=8$, and $\mathrm{p}_{1}=6.5$

As omnichannel retail price $p_{2}$ goes up, $R_{2}$ steadily loses its market share while $R_{1}$ 's market share increases. However, the decrease in $R_{2}$ 's market share is steeper than the increase in $R_{1}$ 's market share. In Figure 1, segment III represents those customers who derive positive utility from both $R_{1}$ and $R_{2}$, but higher utility from retailer $R_{2}$. Higher $p_{2}$ would push the point $\left(p_{2}-p_{1}, 0\right)$ towards the right, and the point $\left(R-p_{1}, \frac{R-p_{2}}{R-p_{1}}\right)$ downward. As a result, as $p_{2}$ goes up, the area of segment III shrinks leading to an increase in the size of segment II. Thus some customers will switch over to $R_{1}$. In addition, higher $p_{2}$ would also push $\left(H, \frac{R-p_{2}}{H}\right)$ point downward leading to shrinking of the area for segment IV. Reduction in customers from segment IV due to higher $p_{2}$ does not add to $R_{1}$ 's market share, as these customers do not derive positive utility from $R_{1}$. In the above example, $5.17 \%$ of the market who have been buying from $R_{2}$ at $p_{2}=7$ become non-buyers as $p_{2}$ becomes 7.5.

Thus, increasing $p_{2}$ makes $R_{2}$ lose market share from both segments III and IV. However, changes in areas of segments III and IV impact $R_{2}$ 's market share differently.

Proposition 2: At an omnichannel price $p_{2}, R_{2}$ 's market share coming from segment III, representing customers drifting away from $R_{1}$, is given by $\frac{1}{H}\left\{\left(R-p_{2}\right)-\left(p_{2}-\right.\right.$ $\left.\left.p_{1}\right) \ln \left(\frac{R-p_{1}}{p_{2}-p_{1}}\right)\right\}$. As price $p_{2}$ goes up in comparison to $p_{1}$, the size of segment III comes down exponentially and the rate of decrease is given by $\frac{1}{H} \ln \left(\frac{p_{2}-p_{1}}{R-p_{1}}\right)$.

As is evident from the expression for the rate of decrease, a lower $p_{1}$ would result in a higher $\frac{1}{H} \ln \left(\frac{p_{2}-p_{1}}{R-p_{1}}\right)$ value. This implies that a lower $p_{1}$ would lead to the size of segment III decreasing at a lower rate with increasing $p_{2}$ and vice versa.

We consider the same scenario used earlier $-R=10$ $H=8$, and $p_{1}=6.5-$ to see the effect of $p_{2}$ on the size of segment III. $R_{2}$ 's market share coming from segment III has been plotted in Figure 3 for different $p_{2}$ values. When $p_{1}=$ 6.5 , retailer $R_{2}$ manages to lure away $15.59 \%$ of the target market from its competitor $R_{1}$ by setting $p_{2}$ at 7.5. However, when $p_{2}$ is set at 8 and 8.5 , the corresponding market shares from segment III come down to approximately $9.11 \%$ and 
$4.76 \%$, respectively. Moreover, the rate of decrease in the size of segment III with increasing $p_{2}$ is lower when $p_{1}=$ 6.5 compared to when $p_{1}=7$.

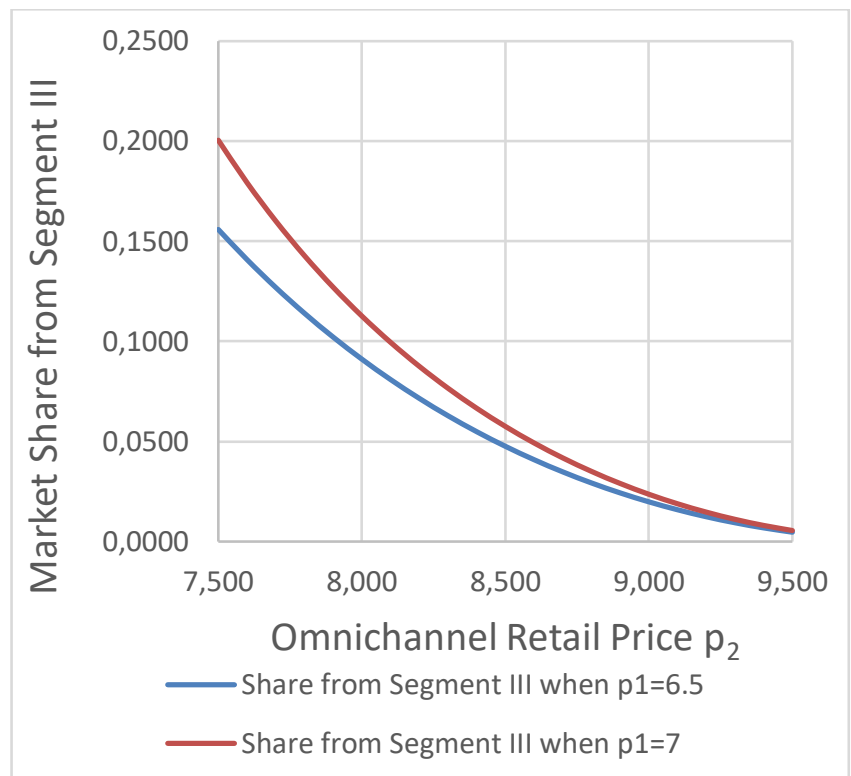

Figure 3 Market share $\mathrm{R}_{2}$ lures away from $\mathrm{R}_{1}$ when $\mathrm{R}=10$ and $\mathrm{H}=8$

As mentioned earlier, segment IV represents the increase in the extent of market penetration due to the entry of omnichannel retailer $R_{2}$. The size of segment IV would depend on the share of the potential market that stayed away from retailer $R_{1}$ when $R_{1}$ alone was serving the market. When $p_{1}$ is low, $\left(R-p_{1}\right)$ would provide enough cushion to the customers to adjust themselves to the extent of 'effort cost' associated with traditional channels before they stop deriving positive utility from $R_{1}$. Hence the untapped market would also be low, and $R_{2}$ 's opportunity to convert nonbuyers to buyers would be low. Thus only when the price $p_{1}$ charged by the incumbent retailer $R_{1}$ is relatively high would the new entrant $R_{2}$ get some room for market penetration. Moreover, a higher $p_{2}$ means that customers would derive lower utility from $R_{2}$. Hence, increasing $p_{2}$ is expected to result in decreasing size of segment IV.

Proposition 3: At an omnichannel price $p_{2}, R_{2}$ 's market share coming from segment IV, representing the increase in market penetration due to $R_{2}$ 's entry, is given by $\frac{1}{H}\left\{\left(R-p_{2}\right) \ln \left(\frac{H}{R-p_{1}}\right)\right\}$. As price $p_{2}$ goes up in comparison to $p_{1}$, the area of the segment IV comes down linearly at the rate of $\frac{1}{H} \ln \left(\frac{R-p_{1}}{H}\right)$.

It is interesting to note that the rate of decrease is independent of $p_{2}$. Moreover, it is evident from the expression that a lower $p_{1}$ would result in a higher $\frac{1}{H} \ln \left(\frac{R-p_{1}}{H}\right)$ value. This implies that a lower $p_{1}$ would lead to the size of segment IV decreasing at a lower rate with increasing $p_{2}$ and vice versa.

Continuing with the same example $-R=10, H=8$, and $p_{1}=6.5-$ Figure 4 plots $R_{2}$ 's market share coming from segment IV with increasing $p_{2}$. The size of segment IV decreases at a lower rate when $p_{1}=6.5$ compared to when $p_{1}=7$.

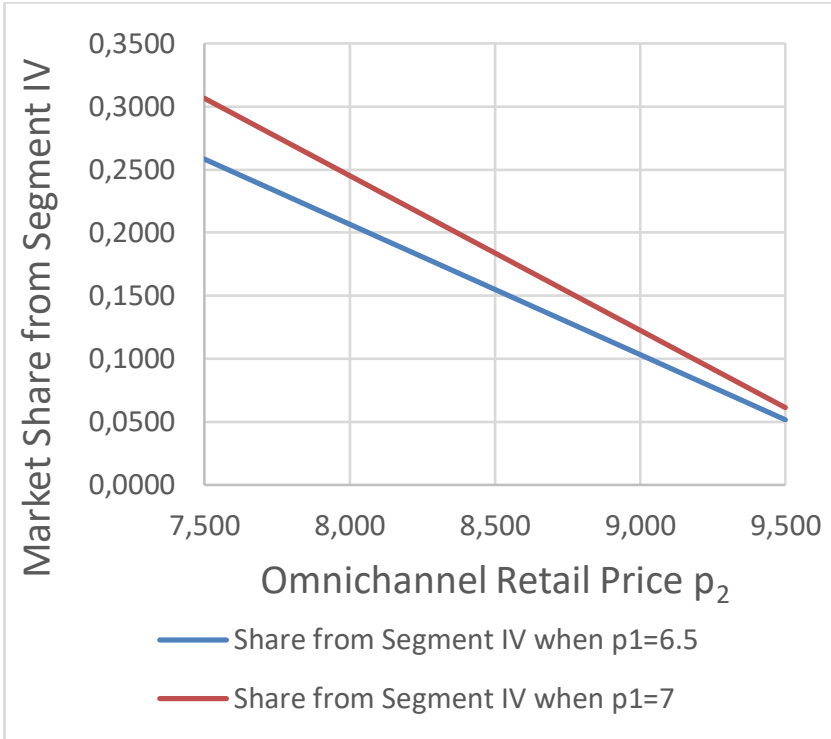

Figure 4 Increase in market penetration due to $\mathrm{R}_{2}$ 's entry when $\mathrm{R}=10$ and $\mathrm{H}=8$

\subsection{Partial Omnichannel Flexibility $(0<b<$ 1) at Price $p_{2}$}

Provisioning of full flexibility implies that $p_{2}$ should be high enough so that the additional revenue earned by charging an additional $\left(p_{2}-p_{1}\right)$ amount per unit product sold would suffice to offset the additional cost retailer $R_{2}$ incurs in establishing requisite integration mechanisms. However, as $p_{2}$ goes up, the points $\left(R-p_{1}, \frac{R-p_{2}}{R-p_{1}}\right)$ and $\left(H, \frac{R-p_{2}}{H}\right)$ in Figure 1 move downward and the point $\left(p_{2}-p_{1}, 0\right)$ moves to the right. The combined effect leads to shrinking of segments III and IV. Since these segments constitute retailer $R_{2}$ 's market share, as $p_{2}$ goes up to recover cost of acquiring omnichannel capabilities, the market share of retailer $R_{2}$ comes down. To compensate for the revenue shortfall arising from $R_{2}$ 's diminishing market share, $p_{2}$ needs to be increased further leading to a vicious circle. Faced with this problem, retailer $R_{2}$ may decide to offer only a limited level of omnichannel flexibility $(0<b<1)$ so that the consequent higher price $p_{2}$ to be charged would still bring in sufficient market share to make the business model sustainable. Most of the players currently offering omnichannel services in different markets across the world belong to this category. These retailers started operating primarily as offline or online retailers and later integrated a limited set of complementary online or offline services, respectively, to become omnichannel entities. Partial flexibility arising from this limited set of omnichannel services implies that the concerned 'effort reduction factor' $\beta$ would have limited ability in reducing effort cost of the customers. In this situation, the lower support of $\beta$ would assume a value $b, 0<b \leq 1$. We would like to see how would retailer $R_{2}$ perform if, for a given price $p_{2}\left(p_{2}>p_{1}\right)$, the effort cost can be brought down by a factor no greater than $b$. On the basis of values of $b$, the rectangle $\left\{\left(h_{1}, \beta\right) \mid h_{1} \in[0, H], \beta \in[0,1]\right\}$ of Figure 1 can be split into three regions as shown in Figure 5. 


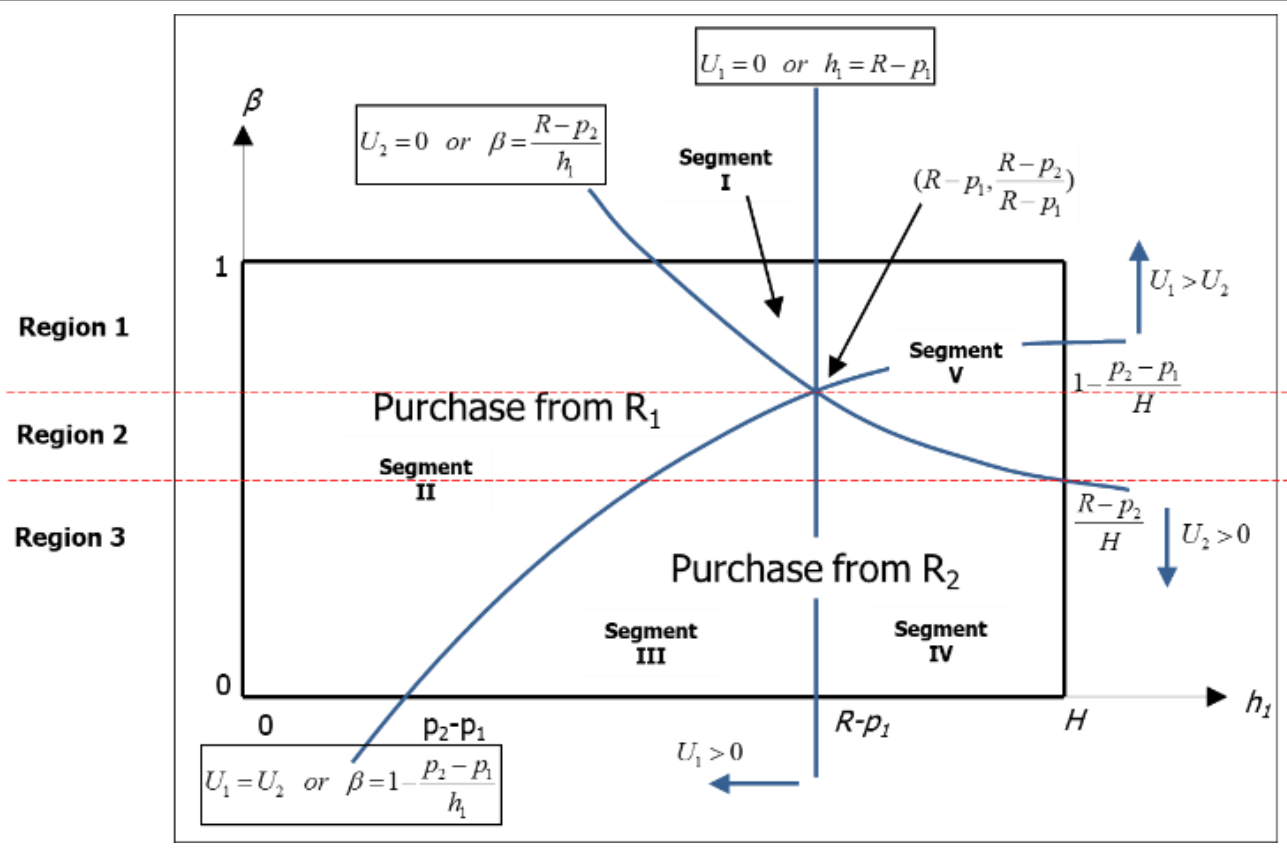

Figure 5 Regions of possible b values attained by $\mathrm{R}_{2}$

Table 2 Market shares captured by $\mathrm{R}_{1}$ and $\mathrm{R}_{2}$ in a competitive setting

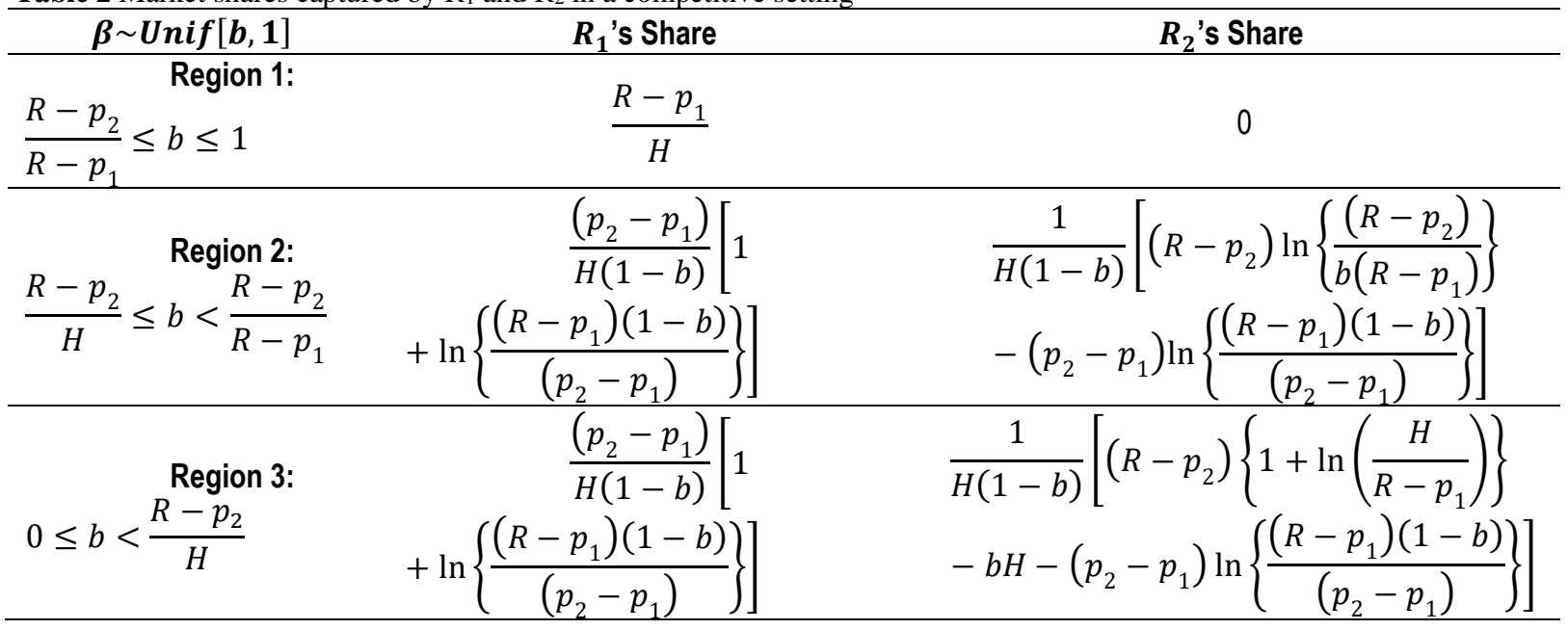

Table 3 Market shares of $\mathrm{R}_{1}$ and $\mathrm{R}_{2}$ for different values of $\mathrm{b}$

\begin{tabular}{|c|c|c|c|c|}
\hline \multirow{2}{*}{$\beta \sim \operatorname{Unif}[b, 1]$} & \multicolumn{2}{|c|}{ Contributions to $R_{2}$ 's Shares } & \multirow{2}{*}{$R_{2}$ 's Total Share } & \multirow{2}{*}{$R_{1}$ 's Share } \\
\hline & Segment III & Segment IV & & \\
\hline$b=0$ & $20.17 \%$ & $25.99 \%$ & $46.16 \%$ & $29.83 \%$ \\
\hline$b=\frac{R-p_{2}}{H}=0.375$ & $11.67 \%$ & $11.59 \%$ & $23.26 \%$ & $38.33 \%$ \\
\hline$b=\frac{R-p_{2}}{R-p_{1}}=0.75$ & 0 & 0 & 0 & $50 \%$ \\
\hline$b=1$ & 0 & 0 & 0 & $50 \%$ \\
\hline
\end{tabular}

The market share captured by $R_{1}$ or $R_{2}$ in a particular scenario would depend on which particular region the concerned $b$ value belongs to. The following proposition is obvious for Region 1 of Figure 5.

Proposition 4: Retailer $R_{2}$ will not get any share of the market unless the omnichannel set of services provided at a price $p_{2}$ can lead $b$, i.e., the lower support of $\beta$ 's distribution, to assume values lower than $\frac{R-p_{2}}{R-p_{1}}$, i.e., retailer $R_{2}$ 's market share will be zero if, at price $p_{2}, \beta$ is distributed over the interval $\left[\frac{R-p_{2}}{R-p_{1}}, 1\right]$.

For example, assume $R=10, H=8$, and $p_{1}=6$. If retailer $R_{2}$ decides to charge a retail price $p_{2}=7$, it would have to ensure a minimum level of omnichannel services that would push $b$ to assume a value lower than 0.75 ; otherwise, $R_{2}$ will not be able to capture any market share.

Proposition 5: The market shares captured by retailers $R_{1}$ and $R_{2}$ at different values of $b$ will be as given in Table 2 . 
We consider a numerical example with the following values, $R=10, H=8, p_{1}=6$, and $p_{2}=7$. Market shares of retailers $R_{1}$ and $R_{2}$ at certain values of $b$ will be as shown in Table 3.

At the given higher price $p_{2}, R_{2}$ needs to offer enough flexibility that would bring $b$ below 0.75 , before it can expect to capture any market share. Even if $R_{2}$ manages to pull down $b$ 's value to 0.375 at that price, its market share will still be substantially less than that of $R_{1}$. The highest market share that $R_{2}$ can expect to achieve is $46.16 \%$, if it is able to provide full flexibility, i.e., $b=0$, at this price.

\subsection{Cost of Omnichannel Integration and Consequent Market Share of $R_{2}$}

From Proposition 5, $R_{2}$ 's market share is sensitive to $p_{2}$ and the extent of flexibility that can be arranged at that price. Thus an omnichannel retailer's sustainability would depend on the amount of 'effort cost' that can be reduced at a price $p_{2}$ that is as close to incumbent retail price $p_{1}$ as possible. The amount of flexibility that can be arranged by the retailer at a given price differential $p_{2}-p_{1}$ will depend on two factors. Firstly, it would depend on $\eta$, an efficiency parameter for the concerned retailer's efforts in integrating services across channels. The parameter $\eta$ reflects the organizational and operational readiness of an omnichannel retailer, i.e., how aligned the concerned retailer currently is to facilitate integration of services. Integrated organizational structure instead of channel-separated units (Hübner et al., 2016), well-aligned channel incentives (Gallino \& Moreno, 2014), ICT-based enterprise-wide cooperation and collaboration systems (Li et al., 2015), and optimized channel-operations (Simone \& Sabbadin, 2017) are some of the factors which differentiate an omnichannel-ready retailer from others. A lower $\eta$ value refers to higher organizational and operational readiness and hence more cost-effective omnichannel implementation, and vice versa. Secondly, it would depend on the cost function $f(1-b)$ that decides the cost to be incurred to integrate services that would bring down the lower support of $\beta$ to $b$. The cost function $f(1-$ $b)$ only considers ongoing cost of service integration needed for omnichannel value provisioning. We do not consider any fixed cost component - e.g., infrastructure establishment, IT capability procurement, etc. - applicable to this purpose. Similar to Mukhopadhyay et al., (2008), we consider $f(1-b)$ to assume convex form to accommodate the condition that reducing a large quantum of effort cost would be proportionately costlier than reducing a lower amount of the same. This means lower the value of $b$, i.e., higher the extent of omnichannel flexibility, proportionately costlier would be the associated integration efforts.

Let $c_{1}$ be the cost of serving a customer by the retailer $R_{1}$. Cost $c_{1}$ does not include cost of production that, without loss of generality, has been assumed to be zero for both $R_{1}$ and $R_{2}$. The additional cost of providing omnichannel flexibility would depend on the intrinsic efficiency parameter $\eta$ of $R_{2}$, and the cost function $f(1-b)$ it faces for integrating services and we assume it to take the form $c_{1} *$ $\eta * f(1-b)$. The price $p_{2}$ to be charged by the omnichannel retailer would then become:

$$
p_{2}=p_{1}+c_{1} * \eta * f(1-b)
$$

Given a cost function for integration, Table 2 can now be used to find the achievable market share of $R_{2}$ in terms of $p_{1}$, the price being charged by the competitor $R_{1}$, and $\eta$, the inherent efficiency of integration of $R_{2}$ for different values of flexibility offered. It can also be used to see if a target market share of $R_{2}$ is achievable or not.

For example, let $R=10, H=8, c_{1}=3$. Let us assume that $R_{1}$ has already set its retail price as $p_{1}=\frac{\left(R+c_{1}\right)}{2}=6.5$ to maximize its profit (as $R_{1}$ 's profit expression is given by: $\Pi_{R_{1}}=\left(p_{1}-c_{1}\right) * \frac{\left(R-p_{1}\right)}{H}$, which can be maximized by setting $p_{1}$ equal to $\left.\frac{\left(R+c_{1}\right)}{2}\right)$. Let us also assume that retailer $R_{2}$ targets a market share of $50 \%$. Given its inherent efficiency coefficient of omnichannel integration $\eta$, what value of $b$ it must achieve such that the corresponding price $p_{2}$ would bring the retailer a market share of $50 \%$ ? In other words, given a target market share how much 'effort cost' it must reduce given its efficiency of omnichannel integration? We consider two convex forms for $f(1-b)$ - exponential, i.e., $\exp (1-b)$, and quadratic, i.e., $(1-b)^{2}$. Using Table 2, we find out the extent of flexibility that retailer $R_{2}$ must achieve for different efficiency coefficients of omnichannel integration to achieve $50 \%$ market share. The corresponding $b$ values have been plotted against increasing $\eta$ values in Figure 6(a) and 6(b).
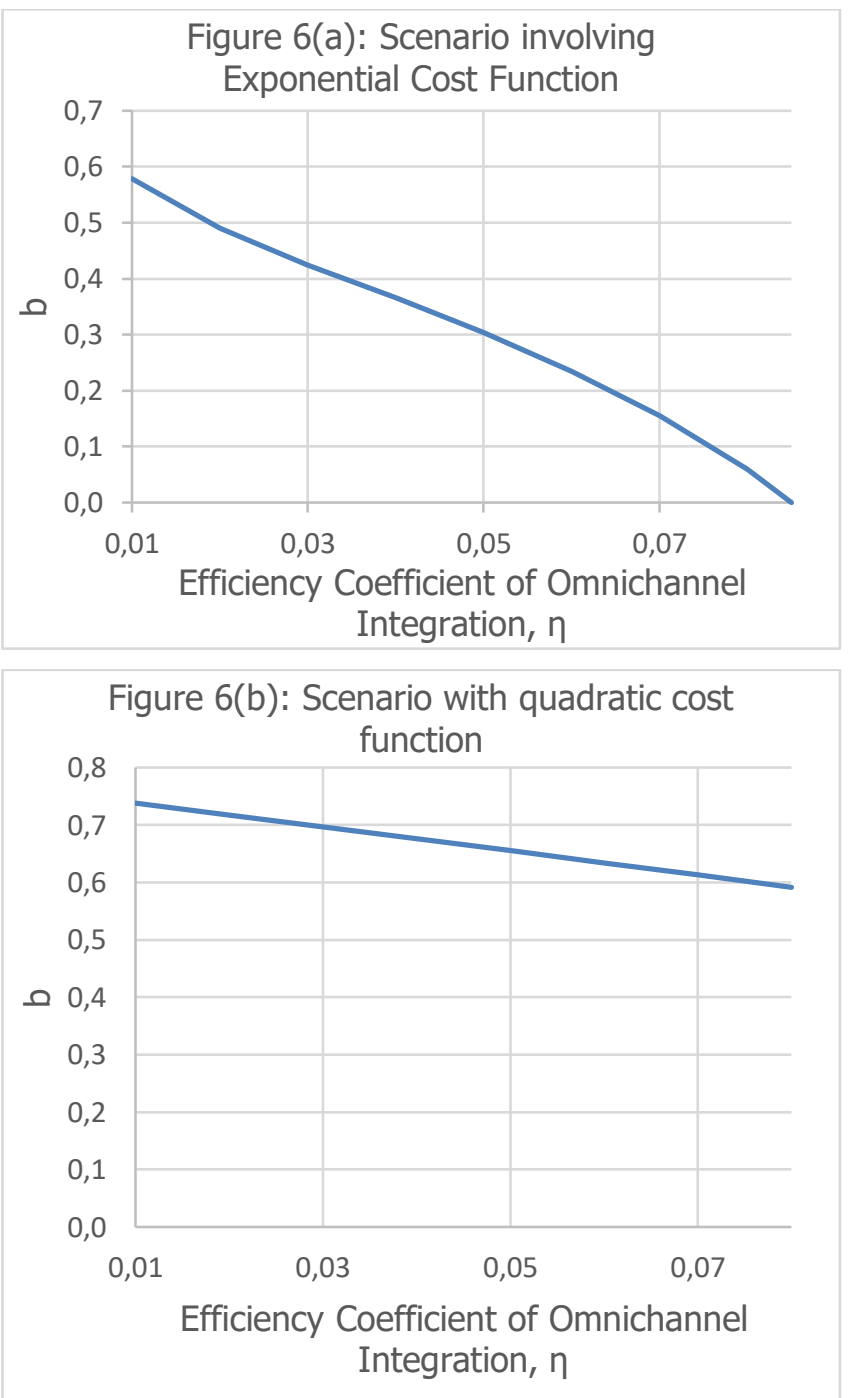

Figure 6 Required b values to achieve a market share of 50\% 
With exponential cost function, retailer $R_{2}$ cannot achieve $50 \%$ market share if its efficiency coefficient of omnichannel integration, $\eta$ is more than 0.085 . With the value of the efficiency parameter as low as 0.01 , retailer $R_{2}$ must achieve a $b$ value of less than 0.58 to capture half of the market. If $\eta$ is $0.085, R_{2}$ has to offer full flexibility (i.e., $b=$ 0 ) to capture $50 \%$ market share. At $\eta=0.09, R_{2}$ will get $48.8 \%$ market share even with full flexibility. However, when the cost function is not as steep as exponential, and is quadratic, 50\% market share is achievable even when the efficiency coefficient of omnichannel integration is as high as 0.23 .

\section{This leads us to the following proposition:}

Proposition 6: For an omnichannel retailer with its inherent efficiency of omnichannel integration, there exists a limit on the market share the retailer can achieve, and this limit depends on the applicable cost function for service integration.

In other words, the efficiency of integration and the applicable cost function impose a restriction on the performance of the concerned omnichannel retailer as, given an $\eta$ and a cost function $f(1-b)$, retailer $R_{2}$ cannot aspire to achieve beyond a certain share of the market.

\section{DISCUSSION}

In this paper, we have developed an analytical model that captures the cost implications of becoming an omnichannel retailer, and its consequent impact on the retailer's market share. Integration of services across channels entails cost, which an omnichannel retailer would try to recover from its customers. The integration that a retailer can achieve at a given price would depend on its inherent efficiency coefficient of integration and the cost function for integrating services. Conceptually, omnichannel can be considered an overlay on top of the offline and channels of the retailer. The omnichannel layer is supposed to facilitate each underlying channel to interact with and complement the other to provide omnichannel services. Customers' expectations and technological innovations will ever be evolving, thereby always exerting pressure on an omnichannel aspirant's existing operations and integrations. Hence, the retailer needs to have systems in place which will help it expect changes, design appropriate responses, and accordingly tune operations that would facilitate the change without adverse impacts on the existing services (Mirsch, Lehrer, \& Jung, 2016). The inherent efficiency coefficient of integration acts as a proxy of the omnichannel readiness of the retailer, lower the value higher the readiness. In addition to reflecting the cost implications of the channel integration mechanisms put in place, it also indicates how easily changes in information, process or product flows across channels can be arranged to offer the next omnichannel service.

The market's response to the enhanced services and the higher price would depend on two independent sources of customer heterogeneity. From available studies in literature, customers are known to be heterogeneous in their perceived inconvenience - and, hence, in their effort costs - while buying from non-omnichannel retailers. However, customers will also be heterogeneous in their perceived reduction in effort cost due to introduction of an omnichannel service. The interplay of these two heterogeneities results in different valuations of the enhanced omnichannel flexibility by different customers. This trade-off between higher price demanded and enhanced value offered segments the market between the omnichannel retailer and its competitors. Omnichannel retailer's market share would come from two segments. Firstly, for some customers having positive net utility from both types of retailers, the net utility will be higher from the omnichannel retailer and they will shift away from the non-omnichannel competitors to the omnichannel retailer. However, the market share captured in this manner is susceptible to the extra price the customers have to pay for omnichannel services, and erodes exponentially as the omnichannel price drifts away from the price charged by non-omnichannel retailers. The second contribution to omnichannel retailer's market share comes from conversion of non-buyers to buyers. When only non-omnichannel retailers were serving the market, some customers would have stayed away from the market because their net utility was negative for the non-channel retailers. The size of such non-buyers would depend on the prices charged by these retailers, lower the price lower is the number of non-buyers. When an omnichannel retailer enters the market, the net utility for a fraction of these customers may become positive because, for them, the reduction in effort cost more than compensates the extra price they are being charged for the omnichannel services. This segment represents the increase in market penetration of the product due to enhanced services. The size of this segment also shrinks as the price charged by the omnichannel retailer goes up. However, the rate of decrease is linear and depends on the price being charged by the non-omnichannel retailers.

It is important to note that unless omnichannel services are provided at no additional cost to the customer, there will always be segments in the market who would have higher positive net utility from the traditional retailers and would remain loyal to them. Given a retailer's inherent efficiency of integration and the cost for integration, it is unlikely that a retailer can sustain offering omnichannel services to customers at no additional cost. Hence, contrary to the perception that omnichannel strategy can make traditional retailers redundant (Bell et al., 2014; Brynjolfsson et al., 2013; Rigby, 2011), there are reasons to believe that both types of retailers would continue to co-exist in the market.

The involvement of multiple channels makes it a challenging exercise to determine the optimal level of channel integration for an omnichannel retailer ("Moving from Multi-Channel to Omni-Channel Retailing," 2020). Our result shows that the market share that an omnichannel entrant can expect depends on an intricate balance of (a) the retail price being charged by existing non-omnichannel retailers; (b) the room available for market penetration; (c) the distribution of the perceived value addition (in terms of effort cost reduction) among the customers; (d) the inherent efficiency of omnichannel integration of the retailer; and (e) the cost function of integration. A retailer can leverage the results to see if the target market holds enough potential for it to enter with an omnichannel model or not. The retailer must have an assessment of the internal efficiency of integration and, if required, may decide to first improve upon it before embarking on the omnichannel journey. The retailer also needs to prioritize the candidate services for integration based on their perceived value addition and integrate only those services that would help him reach a target market 
share as per the results given. On the whole, the model would help an omnichannel aspirant to look into relevant aspects of the existing market, take into consideration its own operational cost structure, and do what-if analyses to see what strategy best suits its goal.

\section{CONCLUDING REMARKS}

The paper analyzes the strategic behavior exhibited by customers in retailer selection when an omnichannel entrant enters a market hitherto served by non-omnichannel retailers, and demonstrates the importance of the underlying economic rationale in determining the outcome. To the best of our knowledge, this seems to be the first attempt to look into the economic aspects of the omnichannel business model.

An omnichannel aspirant needs to invest in integrating services. The cost incurred would depend the efficiency of integration of the retailer and the extent of omnichannel flexibility offered. To recover the cost, the retailer would offer the enhanced services by charging a price higher than its non-omnichannel rivals. The proposed model finds analytical expressions for the market shares in terms of incumbent retail price, customer-specific reduction in effort cost induced by omnichannel flexibility, and the cost of enabling omnichannel flexibility. The findings delineate the pivotal role played by the trade-off between omnichannel value delivery and corresponding cost implications in determining long-term financial sustainability of an omnichannel business model.

The study aims to advance the research on omnichannel retailing by identifying factors that determine omnichannel performance in a competitive setting. The analysis also demonstrates how a retailer can enhance its attractiveness to the customers by trading off the level of omnichannel flexibility it offers with the cost it incurs in doing so.

The work reported here can be extended in a few of directions. Firstly, we have coalesced all existing nonomnichannel retailers into one and assumed a single range of effort cost for customers purchasing from it. This assumption serves us well as our objective in this paper is not to compare between the performances of non-omnichannel retailers adopting different channel strategies - offline, online, or even multichannel; rather it allows us to evaluate an omnichannel retailer's performance when it is competing with a bunch of non-omnichannel retailers for market share. While considering separate ranges of effort costs for offline, online, and omnichannel retailers might give us a more complete picture, but the resulting model may very soon become mathematically cumbersome to handle. Secondly, our model assumes that the existing non-omnichannel retailers do not react to the entry of the omnichannel retailer. In reality, one can expect a price war to set in and it would be interesting to investigate the competitive performance of the omnichannel entrant in the face of different pricing responses from the incumbents.

\section{REFERENCES}

4 Tips for Creating a Valuable Omnichannel Customer Experience. (2017, April 20). The Wall Street Journal. Retrieved from https://partners.wsj.com/ups/4-tips-for-creating-a-valuableomnichannel-customer-experience/

Abdulkader, M. M. S., Gajpal, Y., \& ElMekkawy, T. Y. (2018). Vehicle Routing Problem in Omni-Channel Retailing
Distribution Systems. International Journal of Production Economics, 196(February), pp. 43-55. https://doi.org/10.1016/j.ijpe.2017.11.011

Ailawadi, K. L., \& Farris, P. W. (2017). Managing Multi- and Omni-Channel Distribution: Metrics and Research Directions. Journal of Retailing, 93(1), pp. 120-135. https://doi.org/10.1016/j.jretai.2016.12.003

Bell, D. R., Gallino, S., \& Moreno, A. (2014). How to Win in an Omnichannel World. MIT Sloan Management Review, 56(1), pp. $45-54$.

Brynjolfsson, E., Hu, Y. J., \& Rahman, M. S. (2013). Competing in the Age of Omnichannel Retailing. MIT Sloan Management Review, 54(4), pp. 23-29.

Cattani, K., Gilland, W., Heese, H. S., \& Swaminathan, J. (2006). Boiling Frogs: Pricing Strategies for a Manufacturer Adding a Direct Channel that Competes with the Traditional Channel. Production and Operations Management, 15(1), pp. 40-56.

Click \& Collect from Our Shop. (n.d.). Retrieved November 8, 2018, from John Lewis and Partners website: https://www.johnlewis.com/customer-services/deliveryinformation/click-and-collect

Dennis, S. (2018, December 26). The 3 Big Problems With Omnichannel Retail. Forbes.Com. Retrieved from https://www.forbes.com/sites/stevendennis/2018/12/26/the3-big-problems-with-omnichannel-retail/\#3d9d58f43fc4

Gallino, S., \& Moreno, A. (2014). Integration of Online and Offline Channels in Retail: The Impact of Sharing Reliable Inventory Availability Information. Management Science, 60(6), pp. 1434-1451.

Gao, F., \& Su, X. (2017a). Omnichannel Retail Operations with Buy-Online-and-Pick-up-in-Store. Management Science, 63(8), pp. 2478-2492. https://doi.org/10.1287/mnsc.2016.2473

Gao, F., \& Su, X. (2017b). Online and Offline Information for Omnichannel Retailing. Manufacturing \& Service Operations Management, 19(1), pp. 84-98.

Gao, F., \& Su, X. (2018). Omnichannel Service Operations with Online and Offline Self-Order Technologies. Management Science, 64(8), pp. 3595-3608. https://doi.org/10.1287/mnsc.2017.2787

Gu, Z. J., \& Tayi, G. K. (2017). Consumer Pseudo-Showrooming and Omni-Channel Product Placement Strategies. MIS Quarterly, 41(2), pp. 583-606. https://doi.org/10.25300/MISQ/2017/41.2.11

Gunnilstam, J. (2016). Debate: Omnichannel a Big Failure? Retrieved November 8, 2018, from Economy.com website: http://www.ecomony.com/Omnichannel-a-BigFailure, 7371.html

Hansen, R., \& Sia, S. K. (2015). Hummel's Digital Transformation Toward Omnichannel Retailing: Key Lessons Learned. MIS Quarterly Executive, 14(2), pp. 51-66.

Harsha, P., Subramanian, S., \& Uichanco, J. (2019). Dynamic Pricing of Omnichannel Inventories. Manufacturing and Service Operations Management, 21(1), pp. 47-65. https://doi.org/10.1287/msom.2018.0737

Hossain, T. M. T., Akter, S., Kattiyapornpong, U., \& Wamba, S. F. (2017). The Impact of Integration Quality on Customer Equity in Data Driven Omnichannel Services Marketing. Procedia Computer Science, 121, pp. 784-790. https://doi.org/10.1016/j.procs.2017.11.101

Hübner, A., Wollenburg, J., \& Holzapfel, A. (2016). Retail Logistics in the Transition from Multi-Channel to OmniChannel. International Journal of Physical Distribution \& Logistics Management, 46(6/7), 562-583.

Huré, E., Picot-Coupey, K., \& Ackermann, C. L. (2017). Understanding Omni-Channel Shopping Value: A MixedMethod Study. Journal of Retailing and Consumer Services, 39(November), pp. 314-330. https://doi.org/10.1016/j.jretconser.2017.08.011

Ilk, N., Brusco, M., \& Goes, P. (2018). Workforce Management in 
Omnichannel Service Centers with Heterogeneous Channel Response Urgencies. Decision Support Systems, 105(January), pp. 13-23. https://doi.org/10.1016/j.dss.2017.10.008

Ishfaq, R., Defee, C. C., Gibson, B. J., \& Raja, U. (2016). Realignment of the Physical Distribution Process in OmniChannel Fulfillment. International Journal of Physical Distribution \& Logistics Management, 46(6/7), 543-561.

Larke, R., Kilgour, M., \& O'Connor, H. (2018). Build Touchpoints and They Will Come: Transitioning to Omnichannel Retailing. International Journal of Physical Distribution \& Logistics Management, 48(4), pp. 465-483. https://doi.org/10.1108/IJPDLM-08-2014-0215

Li, Q., Luo, H., Xie, P. X., Feng, X. Q., \& Du, R. Y. (2015). Product Whole Life-Cycle and Omni-Channels Data Convergence Oriented Enterprise Networks Integration in a Sensing Environment. Computers in Industry, 70(June), pp. 23-45. https://doi.org/10.1016/j.compind.2015.01.011

Li, Y., Liu, H., Lim, E. T. K., Goh, J. M., Yang, F., \& Lee, M. K. O. (2018). Customer's Reaction to Cross-Channel Integration in Omnichannel Retailing: The Mediating Roles of Retailer Uncertainty, Identity Attractiveness, and Switching Costs. Decision Support Systems, 109(May), pp. 50-60. https://doi.org/10.1016/j.dss.2017.12.010

Mirsch, T., Lehrer, C., \& Jung, R. (2016). Transitioning to an Omnichannel Approach: A Dynamic Capability Perspective. ICIS 2016 Proceedings, 1-12. Retrieved from https://aisel.aisnet.org/cgi/viewcontent.cgi?article=1120\&co ntext=icis 2016

Moving from Multi-Channel to Omni-Channel Retailing. (2020). Retrieved February 2, 2020, from Journal of Retailing and Consumer Services website: https://www.journals.elsevier.com/journal-of-retailing-andconsumer-services/call-for-papers/moving-from-multichannel-to-omni-channel-retailing

Mukhopadhyay, S. K., Zhu, X., \& Yue, X. (2008). Optimal Contract Design for Mixed Channels Under Information Asymmetry. Production and Operations Management, 17(6), pp. 641-650. https://doi.org/10.3401/poms.1080.0069

Petersen, C. (2017). Which is More Expensive - Omnichannel or Retail Stores? Retrieved November 8, 2018, from Customer Think website: http://customerthink.com/which-is-moreexpensive-omnichannel-or-retail-stores/

Picot-Coupey, K., Huré, E., \& Piveteau, L. (2016). Channel Design to Enrich Customers' Shopping Experiences: Synchronizing Clicks with Bricks in an omni-channel perspective - the Direct Optic case. International Journal of Retail \& Distribution Management, 44(3), pp. 336-368. https://doi.org/10.1108/02656710210415703

Piotrowicz, W., \& Cuthbertson, R. (2014). Introduction to the Special Issue Information Technology in Retail: Toward Omnichannel Retailing. International Journal of Electronic Commerce, 18(4), pp. 5-16. https://doi.org/10.2753/JEC1086-4415180400

Rey-garcía, M., Otero, A. R., \& Mato-santiso, V. (2018). The Challenges of Digital Transformation for Fast-Fashion Brands: A Proposal for an Operational Tool to Measure Omni-Channel Integration. In F. J. Martínez-López, J. C. Gázquez-Abad, \& A. Chernev (Eds.), Advances in National
Brand and Private Label Marketing (pp. 95-103). https://doi.org/10.1007/978-3-319-92084-9

Rigby, D. (2011). The Future of Shopping. Harvard Business Review, 89(12), pp. 1-17.

Ruddick, G. (2015, July 1). John Lewis to Charge £2 for Click-andCollect. The Telegraph. Retrieved from https://www.telegraph.co.uk/finance/newsbysector/retailand consumer/11711534/John-Lewis-to-charge-2-for-click-andcollect.html

Saghiri, S. S., Bernon, M., Bourlakis, M., \& Wilding, R. (2018). Omni-Channel Logistics Special Issue. International Journal of Physical Distribution \& Logistics Management, 48(4), pp. 362-364. https://doi.org/10.1108/IJPDLM-08-2014-0215

Shen, X.-L., Li, Y.-J., Sun, Y., \& Wang, N. (2018). Channel Integration Quality, Perceived Fluency and Omnichannel Service Usage: The Moderating Roles of Internal and External Usage Experience. Decision Support Systems, 109(May), pp. 61-73. https://doi.org/10.1016/j.dss.2018.01.006

Simone, A., \& Sabbadin, E. (2017). The New Paradigm of the Omnichannel Retailing: Key Drivers, New Challenges and Potential Outcomes Resulting from the Adoption of an Omnichannel Approach. International Journal of Business and Management, 13(1), pp. 85 https://doi.org/10.5539/ijbm.v13n1p85

Vandenbosch, M. B., \& Weinberg, C. B. (1995). Product and Price Competition in a Two-Dimensional Vertical Differentiation Model. Marketing Science, 14(2), pp. 224-249.

von Briel, F. (2018). The future of Omnichannel Retail: A FourStage Delphi Study. Technological Forecasting and Social Change, 132(February), pp. 217-229. https://doi.org/10.1016/j.techfore.2018.02.004

Wiener, M., Hoßbach, N., \& Saunders, C. (2018). Omnichannel Businesses in the Publishing and Retailing Industries: Synergies and Tensions between Coexisting Online and Offline Business Models. Decision Support Systems, 109(May), pp. 15-26. https://doi.org/10.1016/j.dss.2018.01.008

Williams, C., Aguilar, A., Strusani, D., \& Guthmann, T. (2014). The Omnichannel Opportunity: Unlocking the Power of the Connected Consumer. Retrieved from https://www2.deloitte.com/content/dam/Deloitte/uk/Docume nts/consumer-business/unlocking-the-power-of-theconnected-consumer.pdf

Wollenburg, J., Holzapfel, A., Hübner, A., \& Kuhn, H. (2018). Configuring Retail Fulfillment Processes for Omni-Channel Customer Steering. International Journal of Electronic Commerce, 22(4), pp. 540-575. https://doi.org/10.1080/10864415.2018.1485085

Zacks Equity Research. (2017). Is Omni-Channel the Solution to All Retail Issues? Retrieved November 18, 2017, from Nasdaq website: http://www.nasdaq.com/article/is-omnichannel-the-solution-to-all-retail-issues-cm814787

Zhang, M., Ren, C., Wang, G. A., \& He, Z. (2018). The Impact of Channel Integration on Consumer Responses in OmniChannel Retailing: The Mediating Effect of Consumer Empowerment. Electronic Commerce Research and Applications, 28(March-April), pp. 181-193. https://doi.org/10.1016/j.elerap.2018.02.002 


\section{APPENDIX}

\section{Proof of Proposition 1:}

As shown in Figure 2, market share of $R_{1}$ would come from segment I and II. Similarly, market share of $R_{2}$ will be the sum of the contributions of segments III and IV.

Market share of $R_{1}=$ Area of Segment I + Area of Segment II

$$
\begin{aligned}
& =\frac{1}{H}\left[\left(R-p_{1}\right)-\int_{p_{2}-p_{1}}^{R-p_{1}}\left(1-\frac{p_{2}-p_{1}}{h_{1}}\right) d h_{1}\right] \\
& =\frac{1}{H}\left(p_{2}-p_{1}\right)\left\{1+\ln \left(\frac{R-p_{1}}{p_{2}-p_{1}}\right)\right\}
\end{aligned}
$$

Similarly, Market share of $R_{2}=$ Area of Segment III + Area of Segment IV

$=\frac{1}{H}\left[\int_{p_{2}-p_{1}}^{R-p_{1}}\left(1-\frac{p_{2}-p_{1}}{h_{1}}\right) d h_{1}+\int_{R-p_{1}}^{H}\left(\frac{R-p_{2}}{h_{1}}\right) d h_{1}\right]$

Area of segment III,

$S_{I I I}=\frac{1}{H} \int_{p_{2}-p_{1}}^{R-p_{1}}\left(1-\frac{p_{2}-p_{1}}{h_{1}}\right) d h_{1}=\frac{1}{H}\left\{\left(R-p_{2}\right)-\left(p_{2}-p_{1}\right) \ln \left(\frac{R-p_{1}}{p_{2}-p_{1}}\right)\right\}$

Area of segment IV,

$=\frac{1}{H} \int_{R-p_{1}}^{H}\left(\frac{R-p_{2}}{h_{1}}\right) d h_{1}=\frac{1}{H}\left\{\left(R-p_{2}\right)+\ln \left(\frac{H}{R-p_{1}}\right)\right\}$

Hence, Market share of $R_{2}=$ Area of Segment III + Area of Segment IV

$=\frac{1}{H}\left\{\left(R-p_{2}\right)-\left(p_{2}-p_{1}\right) \ln \left(\frac{R-p_{1}}{p_{2}-p_{1}}\right)\right\}+\frac{1}{H}\left\{\left(R-p_{2}\right)+\ln \left(\frac{H}{R-p_{1}}\right)\right\}$

$=\frac{1}{H}\left[\left(R-p_{2}\right)\left\{1+\ln \left(\frac{H}{R-p_{1}}\right)\right\}-\left(p_{2}-p_{1}\right) \ln \left(\frac{R-p_{1}}{p_{2}-p_{1}}\right)\right]$

\section{Proof of Proposition 2:}

We have shown above that,

$S_{I I I}=\frac{1}{H}\left\{\left(R-p_{2}\right)-\left(p_{2}-p_{1}\right) \ln \left(\frac{R-p_{1}}{p_{2}-p_{1}}\right)\right\}$

Differentiating with respect to $p_{2}$, we get -

$\frac{d S_{I I I}}{d p_{2}}=\frac{d}{d p_{2}}\left[\frac{1}{H}\left\{\left(R-p_{2}\right)-\left(p_{2}-p_{1}\right) \ln \left(\frac{R-p_{1}}{p_{2}-p_{1}}\right)\right\}\right]=\frac{1}{H} \ln \left(\frac{p_{2}-p_{1}}{R-p_{1}}\right)$

Since $p_{1}<p_{2}<R$, we would have $0<\frac{p_{2}-p_{1}}{R-p_{1}}<1$

So, $\frac{1}{H} \ln \left(\frac{p_{2}-p_{1}}{R-p_{1}}\right)$ would assume values less than zero

Moreover, increasing $p_{2}$ would lead to increasing value for $\frac{1}{H} \ln \left(\frac{p_{2}-p_{1}}{R-p_{1}}\right)$

Hence, the market share lured away by $R_{2}$ from $R_{1}$ decreases exponentially (at a decreasing rate) with increasing omnichannel retail price, $p_{2}$. The rate of decrease is given by $\frac{1}{H} \ln \left(\frac{p_{2}-p_{1}}{R-p_{1}}\right)$.

\section{Proof of Proposition 3:}

We have shown earlier that,

$S_{I V}=\frac{1}{H}\left\{\left(R-p_{2}\right) \ln \left(\frac{H}{R-p_{1}}\right)\right\}$

Differentiating with respect to $p_{2}$, we get -

$\frac{d S_{I V}}{d p_{2}}=\frac{d}{d p_{2}}\left[\frac{1}{H}\left\{\left(R-p_{2}\right) \ln \left(\frac{H}{R-p_{1}}\right)\right\}\right]=\frac{1}{H} \ln \left(\frac{R-p_{1}}{H}\right)$

Since $0<R-p_{1}<H$, we would have $0<\frac{R-p_{1}}{H}<1$

So, $\frac{1}{H} \ln \left(\frac{R-p_{1}}{H}\right)$ would assume values less than zero

Hence, the increase in market penetration due to entry of $R_{2}$ decreases linearly with increasing omnichannel retail price, $p_{2}$. The rate of decrease is given by $\frac{1}{H} \ln \left(\frac{R-p_{1}}{H}\right)$. 


\section{Proof of Proposition 5:}

We refer to Figure 2 while calculating market shares for retailers $R_{1}$ and $R_{2}$ for different values of $b$

(i) When $\frac{R-p_{2}}{R-p_{1}} \leq b \leq 1$

The area of the regions representing customers buying from retailer $R_{1}$ $=\left(R-p_{1}\right)(1-b)$

The area of the regions representing customers buying from retailer $R_{2}=0$

(ii) When $\frac{R-p_{2}}{H} \leq b<\frac{R-p_{2}}{R-p_{1}}$

The area of the regions representing customers buying from retailer $R_{1}$

$=\left(R-p_{1}\right)(1-b)-\int_{\frac{p_{2}-p_{1}}{1-b}}^{R-p_{1}}\left\{\left(1-\frac{p_{2}-p_{1}}{h_{1}}\right)-b\right\} d h_{1}=\left(p_{2}-p_{1}\right)\left[1+\ln \left\{\frac{\left(R-p_{1}\right)(1-b)}{\left(p_{2}-p_{1}\right)}\right\}\right]$

The area of the regions representing customers buying from retailer $R_{2}$

$=\int_{\frac{p_{2}-p_{1}}{1-b}}^{R-p_{1}}\left\{\left(1-\frac{p_{2}-p_{1}}{h_{1}}\right)-b\right\} d h_{1}+\int_{R-p_{1}}^{\frac{R-p_{2}}{b}}\left(\frac{R-p_{2}}{h_{1}}-b\right) d h_{1}$
$=\left(R-p_{2}\right) \ln \left\{\frac{R-p_{2}}{b\left(R-p_{1}\right)}\right\}-\left(p_{2}-p_{1}\right) \ln \left\{\frac{\left(R-p_{1}\right)(1-b)}{\left(p_{2}-p_{1}\right)}\right\}$

(iii) When $0 \leq b<\frac{R-p_{2}}{H}$

The area of the regions representing customers buying from retailer $R_{1}$

$=\left(R-p_{1}\right)(1-b)-\int_{\frac{p_{2}-p_{1}}{1-b}}^{R-p_{1}}\left\{\left(1-\frac{p_{2}-p_{1}}{h_{1}}\right)-b\right\} d h_{1}=\left(p_{2}-p_{1}\right)\left[1+\ln \left\{\frac{\left(R-p_{1}\right)(1-b)}{\left(p_{2}-p_{1}\right)}\right\}\right]$

The area of the regions representing customers buying from retailer $R_{2}$

$\begin{aligned}= & \int_{\frac{p_{2}-p_{1}}{1-b}}^{R-p_{1}}\left\{\left(1-\frac{p_{2}-p_{1}}{h_{1}}\right)-b\right\} d h_{1}+\int_{R-p_{1}}^{H}\left(\frac{R-p_{2}}{h_{1}}-b\right) d h_{1} \\ = & \left(R-p_{2}\right)\left\{1+\ln \left(\frac{H}{R-p_{1}}\right)\right\}-b H-\left(p_{2}-p_{1}\right) \ln \left\{\frac{\left(R-p_{1}\right)(1-b)}{\left(p_{2}-p_{1}\right)}\right\}\end{aligned}$

The effective size of the market being considered in these scenarios is $H(1-b)$.

Kushal Saha is a doctoral student at the Indian Institute of Management Calcutta. He did his post-graduation in Business Administration from the Indian Institute of Management Bangalore. His research interests include omnichannel retailing, perishability, retail logistics, sharing economy, and technology-induced disruptions.

Subir Bhattacharya is a Professor in the Management Information Systems Group at the Indian Institute of Management Calcutta. His research interests include efficient algorithms for optimization problems, perishable supply chain management, and software development methodologies. He has published in several academic journals and conferences including European Journal of Operational Research, International Journal of Production Economics, Annals of Operations Research, IEEE Transactions on Systems, Man, and Cybernetics: Systems, and Computers and Chemical Engineering. 